\title{
Rapid and Highly Accurate Prediction of Poor Loop Diuretic Natriuretic Response in Patients With Heart Failure
}

\author{
Jeffrey M. Testani, MD, MTR ${ }^{1,2}$, Jennifer S. Hanberg, BA ${ }^{2}$, Susan Cheng, MD², Veena Rao, \\ $\mathrm{PhD}^{2}$, Chukwuma Onyebeke, $\mathrm{BS}^{2}$, Olga Laur, $\mathrm{MS}^{2}$, Alexander Kula, $\mathrm{MS}^{2}$, Michael Chen, \\ MD ${ }^{1}$, F. Perry Wilson, MD, MSCE ${ }^{1,2}$, Andrew Darlington, MD $^{3}$, Lavanya Bellumkonda, MD¹, \\ Daniel Jacoby, MD¹, W. H. Wilson Tang, MD $^{4}$, and Chirag R. Parikh, MD, PhD ${ }^{1,2}$ \\ ${ }^{1}$ Department of Internal Medicine, Yale University School of Medicine, New Haven, Connecticut \\ 2Program of Applied Translational Research, Yale University School of Medicine, New Haven, \\ Connecticut \\ ${ }^{3}$ Piedmont Heart Institute, Fayetteville, Georgia \\ ${ }^{4}$ Section of Heart Failure and Cardiac Transplantation, the Cleveland Clinic, Cleveland, Ohio
}

\begin{abstract}
Background-Removal of excess sodium and fluid is a primary therapeutic objective in acute decompensated heart failure (ADHF) and commonly monitored with fluid balance and weight loss. However, these parameters are frequently inaccurate or not collected and require a delay of several hours after diuretic administration before they are available. Accessible tools for rapid and accurate prediction of diuretic response are needed.
\end{abstract}

Methods and Results-Based on well-established renal physiologic principles an equation was derived to predict net sodium output using a spot urine sample obtained one or two hours following loop diuretic administration. This equation was then prospectively validated in 50 ADHF patients using meticulously obtained timed 6-hour urine collections to quantitate loop diuretic induced cumulative sodium output. Poor natriuretic response was defined as a cumulative sodium output of $<50 \mathrm{mmol}$, a threshold that would result in a positive sodium balance with twicedaily diuretic dosing. Following a median dose of $3 \mathrm{mg} \mathrm{(2-4} \mathrm{mg)} \mathrm{of} \mathrm{intravenous} \mathrm{bumetanide,} 40 \%$ of the population had a poor natriuretic response. The correlation between measured and predicted sodium output was excellent $(\mathrm{r}=0.91, \mathrm{p}<0.0001)$. Poor natriuretic response could be accurately predicted with the sodium prediction equation (AUC $=0.95,95 \% \mathrm{CI} 0.89-1.0, \mathrm{p}<0.0001$ ). Clinically recorded net fluid output had a weaker correlation $(r=0.66, p<0.001)$ and lesser ability to predict poor natriuretic response ( $\mathrm{AUC}=0.76,95 \%$ CI $0.63-0.89, \mathrm{p}=0.002$ ).

Conclusions-In patients being treated for ADHF, poor natriuretic response can be predicted soon after diuretic administration with excellent accuracy using a spot urine sample.

Correspondence to Jeffrey M. Testani, MD, MTR, Yale University, 60 Temple Street, Suite 6C, New Haven, CT 06510, Tel: (215) 459-3709, Fax: (203) 746-8373, jeffrey.testani@yale.edu.

Disclosures

None. 


\section{Keywords}

diuretics; heart failure; sodium; diuretic resistance; poor natriuretic response

Acute decompensated heart failure (ADHF) is the most common hospital discharge diagnosis among Medicare beneficiaries and accounts for more than half of all heart failure related expenditures. ${ }^{1-3}$ On a population level, ADHF is primarily a disease of congestion, making removal of excess fluid and sodium the primary therapeutic objective in the majority of ADHF hospitalizations. ${ }^{4-7}$ As a result, accurately monitoring the progress and success of diuretic therapy is of critical importance. Serial changes in weight and fluid balance are measures nearly universally employed to monitor decongestion, with their use endorsed by major cardiovascular society guidelines. ${ }^{8-10}$ However, it is widely believed that net fluid output and serial changes in weight are difficult to obtain accurately in practice..$^{9,11-13}$ To that end, we have recently documented in several ADHF populations, including a prospective NIH trial of diuretic strategies, that fluid and weight loss are frequently not collected and when available are surprisingly inaccurate. ${ }^{13}$ Even if these metrics could be consistently and accurately obtained, there is a significant delay between administration of the diuretic, and availability of the data (i.e., "daily weights" are generally obtained only once daily). Between the inconsistent collection, low fidelity, and inherent delay in data availability, diuretics are often titrated only once daily resulting in wasted hospital days before inadequate diuretic response is identified and acted upon.

Adding further complexity to the above uncertainty is the fact that the primary pathophysiology responsible for extracellular volume expansion is sodium retention. ${ }^{14,15}$ However, net fluid and weight loss are almost entirely the result of changes in water balance since water accounts for the vast majority of the weight/volume of even isotonic fluid (i.e., $\sim 9$ grams of $\mathrm{NaCl}$ are in 1000 grams or milliliters of normal saline). As such, if the goal of diuretic therapy is to correct the underlying pathophysiology of sodium overload, the monitoring parameter should ideally predict not only water but also sodium removal. The limited data available in patients with heart failure suggests that significant variability between patients may actually be present in the sodium content of diuretic-induced urine. ${ }^{16}$ Furthermore, even within patients, the sodium content of diuretic induced urine appears to vary considerably over time and with the type of diuretic administered. ${ }^{17}$ Additionally, there appears to be significant prognostic importance of the quantity of sodium in the urine, whereas neither weight nor fluid loss have consistently been linked to outcomes. ${ }^{17-19}$ Unfortunately, performing timed urine collections is not practical in routine clinical practice and would be expected to suffer from many of the same difficult to overcome limitations inherent to monitoring urine output.

Currently, tools that allow early prediction of natriuretic response shortly after administration of a loop diuretic are unavailable. Given the well-understood pharmacokinetics and pharmacodynamics of the loop diuretics, and existing well-validated metrics to query renal filtration and urinary concentration, net sodium and urine output from a dose of diuretic should be accurately predictable from a spot urine sample obtained early after diuretic administration. Glomerular filtration rate (GFR) estimation equations have 
largely replaced and are generally thought to be more accurate than measurement of 24-hour creatinine clearance, in part due to the difficulty of accurately conducting timed urine collections. ${ }^{20}$ Similar to the above example, the ability to rapidly estimate sodium output from a dose of diuretic using an estimating equation could also provide significant value to clinicians and researchers. The goal of the current investigation was to determine if sodium output from a loop diuretic can be rapidly and accurately predicted using well established physiologic principals in conjunction with inexpensive widely available laboratory tests.

\section{Methods}

\section{Equations}

The equations upon which this manuscript is based are not derived from study data, but rather were derived prior to study initiation based entirely upon the well-established tools and physiologic principals available to query renal physiology and diuretic pharmacology. The underlying concept behind the equations is that the instantaneous rate of urine formation at any moment (i.e., milliliters of urine produced per minute) can be described as the glomerular filtration rate (GFR) adjusted for the degree of urinary concentration/dilution occurring in the renal tubules. There is a vast body of literature that has optimized and validated equations for the accurate estimation of GFR (eGFR), which are employed here in the form of the Chronic Kidney Disease Epidemiology Collaboration (CKD-EPI) formula. ${ }^{21}$ Since creatinine undergoes limited reabsorption and secretion in the tubule (the basis for the use of creatinine to estimate GFR) the ratio of serum creatinine to urine creatinine reflects the degree of concentration occurring in the tubules. ${ }^{15}$ As a result, the instantaneous rate of urine formation $(\mathrm{ml} / \mathrm{min})$ can be derived from the product of eGFR and the ratio of serum to urine creatinine. ${ }^{15}$ Multiplication of this parameter by the urine sodium concentration allows conversion from the instantaneous rate of urine formation to sodium excretion $(\mathrm{mmol} / \mathrm{min})$. Since the majority of natriuresis occurs shortly after bolus IV loop diuretic administration, and natriuresis is completed within 6 hours, the instantaneous rate of sodium excretion can be converted into a cumulative sodium output by multiplying by a time constant. ${ }^{22-26} 2.5$ hours was empirically chosen as the constant to convert peak instantaneous natriuresis to cumulative natriuresis because the majority of natriuresis occurs early after intravenous diuretic administration and the half-life of bumetanide is 1 to 1.5 hours (i.e., 2.5 hours would be $\sim 2$ half-lives). ${ }^{21-26}$

The predicted total sodium output was calculated using Equation 1:

$\mathrm{Na}$ output $(\mathrm{mmol})=\mathrm{eGFR} *(\mathrm{BSA} / 1.73) *\left(\mathrm{Cr}_{\text {Serum }} / \mathrm{Cr}_{\text {Urine }}\right) * 60 \mathrm{~min} * 2.5 \mathrm{hr} *\left(\mathrm{Na}_{\text {Urine }} / 1000 \mathrm{ml}\right)$

$\mathrm{Cr}$ represents creatinine in the serum or urine. Body surface area (BSA) was calculated using the Du Bois formula. ${ }^{27}$ The CKD-EPI eGFR was "un-indexed" to $1.73 \mathrm{~m}^{2}$ since absolute sodium output rather than sodium output per $1.73 \mathrm{~m}^{2}$ is the parameter of interest. In patients with extreme obesity (BMI $>40 \mathrm{~kg} / \mathrm{m} 2$ ) ideal body weight (Robinson formula) was used to calculate BSA. $^{28}$

Predicted fluid output was calculated using Equation 2: 
Urine output $(\mathrm{ml})=\mathrm{eGFR} *(\mathrm{BSA} / 1.73) *\left(\mathrm{Cr}_{\text {Serum }} / \mathrm{Cr}_{\text {Urine }}\right) * 60 \mathrm{~min} * 2.5 \mathrm{hr}$

\section{Population}

Patients admitted to the general cardiology and advanced heart failure services at Yale New Haven Hospital were eligible for enrollment. Selection criteria were intentionally broad to attempt to capture a generalizable population of patients undergoing diuresis. Eligibility required a diagnosis of heart failure and a plan by the treating physician for diuresis with intravenous loop diuretics. Exclusion criteria were known bladder dysfunction/ incontinence or an inability to comply with the timed urine collection protocol. Enrollment could occur at any time during the hospitalization at which they met the above criteria. Study data were collected and managed using REDCap (Research Electronic Data Capture) electronic data capture tools hosted at Yale University. ${ }^{29}$ All patients provided written informed consent and the study was approved by the Yale Institutional Review Board.

\section{Urine collection protocol}

Prior to the morning diuretic dosing, the patient was asked to completely empty their bladder. Next, a dose of intravenous loop diuretic was administered. The dose was determined by the treating physician, but all patients in this proof of concept study received bumetanide due to the reproducible pharmacokinetics of this agent. ${ }^{15,26}$ Next, a timed 6hour urine collection with intense supervision by study staff began. This supervision consisted of study personnel stationed outside of the patient's room for the duration of the study with frequent transfer of urine into study collection containers and frequent reinforcement with the patient of the importance of complete collection. Additionally, signs were placed on the door of the patient's room, the bathroom door, and over the toilet reminding patient and staff that all urine was to be saved. A spot urine sample was obtained at hour 1 and hour 2 following the IV diuretic, and the cumulative urine output was also collected, terminating with a forced void at hour 6. A 6-hour time period was chosen since it has been well documented that natriuresis from a dose of IV furosemide or bumetanide is completed within 6 hours. $^{22-25}$

\section{Assays}

Serum creatinine, from the patients' routine morning clinical labs, was obtained from the medical record. Urine creatinine and sodium were determined using a fully automated RxDaytona Clinical Chemistry Analyzer (Randox Laboratories, Ireland, UK). Urine creatinine was determined using a modified Jaffe method and sodium by direct measurement with ion selective electrodes. In the case where urine sodium was below the lower limit of detection, samples were diluted 1:1 with normal saline and re-analyzed. The calibrators, reagents and urine level 2 and level 3 controls were purchased from Randox Laboratories. The inter assay coefficient of variation for the controls were $4.76 \%$ and $4.9 \%$ for creatinine and $4.4 \%$ and $3.71 \%$ for sodium. Assays were conducted using de-identified aliquots of urine, blind to the clinical data from the urine collection protocol (i.e., volume of urine output), and by different study personal than those who obtained the clinical data.

Circ Heart Fail. Author manuscript; available in PMC 2017 January 01. 
Endpoints-The primary endpoint was the ability of Equation 1 to predict a poor loop diuretic natriuretic response, defined as a measured cumulative sodium output of $\mathbf{5 0} \mathbf{m m o l}$ in the 6 hours following the dose of diuretic. The threshold of $\$ 50 \mathrm{mmol}$ was selected because twice daily dosing of the same dose of diuretics would result in $₫ 00 \mathrm{mmol}$ daily $\mathrm{Na}$ output. Since the standard "cardiac diet" at Yale is a $3 \mathrm{gram} / 130 \mathrm{mmol}$ sodium diet, $\unlhd 00 \mathrm{mmol} \mathrm{Na}$ would result in a positive sodium balance. Primary focus was on calculations from the 2-hour spot urine sample as this was hypothesized to be the more accurate of the two time points due to the delay from urine production to availability for collection introduced by the bladder. Secondary endpoints were (1) a suboptimal natriuretic response and (2) an excellent natriuretic response. A suboptimal natriuretic response was defined as $<100 \mathrm{mmol}$ of sodium output from the diuretic which would result in a maximum net sodium deficit of only $70 \mathrm{mmol}$ per day with twice daily diuretic dosing. This is equivalent to a maximum of $<0.5 \mathrm{~L}$ of isotonic fluid or $<1.1 \mathrm{lb}$ per day of weight loss with twice daily dosing, which we feel would be a threshold below which up titration of diuretics should be considered in patients with significant volume overload. An excellent response was defined as $>150 \mathrm{mmol}$ of sodium output in response to the loop diuretic. This would result in $>1 \mathrm{~L}$ of isotonic fluid loss or $>2 \mathrm{lbs}$ with twice daily dosing of diuretics.

\section{Statistical analysis}

Values reported are mean \pm SD, median (quartile 1 - quartile 3) and percentile. Independent Student's $t$ test or the Wilcoxon Rank Sum test was used to compare continuous variables. The chi-square test was used to evaluate associations between categorical variables. Correlation coefficients reported are Pearson's. Receiver operating characteristic curves with calculation of the area under the curve for clinically relevant thresholds of sodium and fluid output (see endpoints section above) were performed. Although the time constant used in the equations does not influence the correlation or area under the curve since it is a linear constant, it will influence the absolute accuracy of the equation particularly at higher sodium outputs. As such, sensitivity analysis was undertaken to determine if the empirically derived constant of 2.5 hours could be improved upon. Sodium output prediction equations with time constants ranging from 2 to 4 hours in 0.25 hour increments were computed. The proportionality of the bias of the equation over the range of sodium output was determined by subtracting the measured sodium output from the predicted sodium output with each time constant and evaluating the correlation with measured sodium output. The time constant resulting in the smallest correlation coefficient was considered the best data driven time constant. Statistical analysis was performed with IBM SPSS Statistics version 21 (IBM Corp., Armonk, NY) and statistical significance was defined as 2-tailed $\mathrm{p}<0.05$.

\section{Results}

Overall, 50 patients completed the 6-hour urine collection protocol and were included in the analysis (Supplemental Figure 1 for cohort assembly details). The median time from hospital admission to enrollment was 4 days (1-7 days). Baseline characteristics of the population are presented in Table 1. Notably, the population consisted predominantly of patients with heart failure with reduced ejection fraction of non-ischemic etiology. Hypertension, diabetes, hyponatremia, and renal dysfunction were common. On average, enrolled patients 
were receiving relatively high doses of loop diuretics with a median diuretic dose of 100 $\mathrm{mg} / 24$ hours of intravenous furosemide equivalents the day prior to the study (Table 1).

The median dose of intravenous bumetanide administered was $3 \mathrm{mg}$ (quartile 1-quartile 3: 2 $-4 \mathrm{mg}$ ) resulting in a mean cumulative sodium output of $85.5 \pm 73 \mathrm{mmol}$ and a mean cumulative urine output of $979 \pm 589 \mathrm{ml}$ over the ensuing 6-hour period. The median diuretic efficiency in this population was $257 \mathrm{ml} / \mathrm{mg}$ bumetanide $(164-486 \mathrm{ml} / \mathrm{mg}$ ), similar to previously reported ADHF populations. ${ }^{18,30}$ Overall, the correlation between the actual cumulative sodium output and the predicted sodium output from Equation 1 was excellent for both the 2-hour sample (Figure 1A and Table 2) and the 1-hour sample (Table 2). The correlation between measured sodium output and the clinically recorded net fluid output for the corresponding $7 \mathrm{am}$ to $3 \mathrm{pm}$ nursing shift (i.e., what the physician would otherwise be making same day dose titration decisions upon) was substantially worse (Table 2 and Figure 1B). The correlation between measured sodium output and parameters such as 24-hour net fluid output, weight change, urine sodium concentration, fractional excretion of sodium and diuretic dose also tended to have a weaker correlation than predicted sodium from Equation 1 (Table 2). Similar to prior reports, the correlation between clinically obtained 24-hour net fluid balance and clinically obtained 24-hour weight loss was modest $(r=0.58, p<0.001)$. The time from hospital admission to diuretic administration did not influence the accuracy of the prediction equation since nearly identical correlations between predicted and measured sodium output were observed ( $\mathrm{r}=0.90 \mathrm{p}<0.001$ vs. $0.91 \mathrm{p}<0.001)$ in patients studied within 48 hours of admission $(n=21$, median time to study $=1$ day) and patients studied $>48$ hours after admission $(n=29$, median time to study $=6$ days). Additionally, in ROC analysis of subgroups defined by patients studied within 48 hours of admission or $>48$ hours after admission, AUC values for prediction of poor natriuretic response (sodium output $<50$ mmol) were similar for both subgroups (AUC $=1.0, \mathrm{p}<0.001,95 \%$ CI $1.0-1.0$ vs. 0.95 , $\mathrm{p}<0.001,95 \%$ CI $0.87-1.0)$.

Poor diuretic natriuretic response ( $\$ 50 \mathrm{mmol}$ sodium output in the 6 hours following the diuretic) occurred in $40 \%$ of the population. In patients with poor natriuretic response, the average cumulative sodium output was $24.3 \pm 12 \mathrm{mmol}$ following a median bumetanide dose of $2.75 \mathrm{mg}$ (2-4 mg). A suboptimal natriuretic response ( $\$ 100 \mathrm{mmol}$ of sodium output) occurred in $68 \%$ of the population. These patients received a median of $3 \mathrm{mg}$ (IQR $2-4 \mathrm{mg}$ ) of bumetanide and excreted $45.0 \pm 28.8 \mathrm{mmol}$ of sodium. In the $16 \%$ of patients that had an excellent natriuretic response (>150 mmol), mean sodium output was $221.1 \pm 52.2 \mathrm{mmol}$ with a bumetanide dose of $3.5 \mathrm{mg}(2-4 \mathrm{mg})$. Particularly with the 2-hour time point, Equation 1 performed remarkably well in predicting which patients would have a poor natriuretic response (Figure 1C). A predicted sodium output from Equation 1 of $\$ 50 \mathrm{mmol}$ was $95 \%$ sensitive and $73 \%$ specific in predicting a poor natriuretic response. A predicted sodium output $<25 \mathrm{mmol}$ was $100 \%$ specific and a predicted sodium output $<75 \mathrm{mmol}$ was $100 \%$ sensitive in predicting a poor diuretic natriuretic response. Overall, Equation 1 had excellent accuracy in predicting all natriuretic thresholds ranging from 50 to $150 \mathrm{mmol}$, with AUC values $\searrow 0.95$ using the 2-hour spot urine and AUC values $\searrow 0.86$ for the 1-hour spot urine time point (Table 3). Operating characteristics of the clinically recorded net fluid output for the corresponding nursing shift were inferior to Equation 1 (Figure 1D) as were 
those of 24-hour fluid and weight loss, particularly at lower sodium output thresholds (Table $3)$.

\section{Time constant sensitivity analysis}

The a priori chosen 2.5 hour time constant appeared to lead to an underestimation of sodium output with progressively higher sodium outputs (Figure 1A and Supplemental Figure 1, $\mathrm{p}<0.001$ ). Analyzing time constants ranging from 2 hours to 4 hours in 0.25 hour increments revealed that the best fit in the current 50 patients was using a constant of 3.25 hours which resulted in stable prediction with progressively larger sodium outputs, as demonstrated by the lack of correlation between observed sodium output and the difference between predicted and observed sodium output $(\mathrm{r}=-0.05, \mathrm{p}=0.74)$.

\section{Prediction of fluid output}

The correlation between measured fluid output in the 6 hours following a dose of loop diuretic and that predicted by equation 2 was $r=0.81, p<0.001$ for the one hour equation and $\mathrm{r}=0.84, \mathrm{p}<0.001$ for the 2-hour equation. AUC values for predicting various levels of measured urine output are presented in Table 4. Overall, prediction of urine output was inferior to prediction of sodium output; however, prediction of urine output by the equation was similar to or better than results achieved using the clinically recorded net fluid output during the corresponding nursing shift in the majority of cases (Table 4).

A web-based calculator for equations $1 \& 2$ can be found at www.CardioRenalResearch.net.

\section{Discussion}

The primary finding of the current analysis is that cumulative sodium output from a dose of loop diuretic can be predicted rapidly and with excellent accuracy from a spot urine sample collected 1 to 2 hours following the dose of loop diuretic. Importantly, derivation of the equations used in this study was not data driven. Rather, the equation was derived from well-established physiologic and pharmacologic principals, and then validated in this real world ADHF population receiving loop diuretics. In addition to the fact that application of this equation allows the possibility of diagnosis and thus provider response to poor diuretic natriuretic response within hours of diuretic administration, it was significantly more accurate in predicting a poor diuretic response than currently available clinical parameters such as net fluid output or weight loss. Although additional research is necessary to understand the appropriate application of these findings, this represents the first description of a new tool to monitor diuretic response with potential use in both research and clinical care in heart failure.

The use of sodium output as a metric of diuretic response is intuitive since physiologically sodium is the principal determinate of extracellular fluid volume and diuretics function primarily via effects on renal sodium channels. ${ }^{31}$ Furthermore, from a practical standpoint measuring sodium rather than fluid balance in hospitalized patients offers several theoretical advantages. Controlling and accounting for actual fluid intake in ADHF patients, who commonly have increased thirst, is a labor-intensive task with many pitfalls since these patients often have free access to water. ${ }^{32}$ However, most hospitalized patients' primary 
source of dietary sodium should be the diet delivered by the hospital nutrition service, making assumptions about intake much simpler. Unfortunately, formally measuring sodium output in clinical practice with standard approaches is burdensome as it requires timed urine collections and obligatorily suffers from the same challenges limiting the accuracy of measuring cumulative fluid output. Notably, in the current study despite 1) the patient and staff knowing they were in a study and needed optimal collection of urine for 6 hours 2) not enrolling patients unlikely to be able to comply with complete urine collection, 3) placing signs in the room and bathroom reminding patient/staff that urine was to be saved 4) a coordinator intensely supervising the timed urine collection, and 5) compensating both patient and the nursing staff during the latter part of the study for the inconvenience of the above interventions, $12 \%$ of patients still had issues with the timed urine collection leading to study cancellation (Supplemental Figure 1). However, a spot urine specimen was obtainable in all patients. As such, the use of a spot urine sample to guide natriuretic therapy provides the advantage of monitoring sodium rather than fluid output and provides this information much more rapidly, accurately, and easily than would be possible with a timed urine collection. Furthermore, given the labor-intensive nature of monitoring fluid intake and output, and the low cost of urine sodium and creatinine, this approach may additionally prove to be more cost effective.

There are several potential direct applications of the current findings to clinical care and research. First, the capability to detect an inadequate natriuresis shortly after diuretic administration offers significant potential opportunity. Given the low fidelity and delay inherent to collection of net fluid balance and change in weight, diuretics are often titrated only once daily. By identifying patients that are responding suboptimally to diuretics just an hour or two after a loop diuretic is given, repeat dosing could occur much more rapidly, offering advantage with respect to outcomes ranging from more rapid symptom relief to possibly a reduction in length of stay or improved overall decongestion. Secondly, in many patients and on many clinical wards it is extremely challenging to accurately monitor diuresis with fluid balance and weight loss. ${ }^{13}$ The current findings provide a tool to allow the clinician to interrogate diuretic responsiveness where otherwise it would be very difficult. Lastly, enrollment into ADHF trials of decongestive therapies should occur early into ADHF therapy. As a result, waiting days to determine that the patient is definitively diuretic resistant by traditional metrics (i.e., failure to lose weight) is suboptimal. However, enrollment of patients that are not diuretic resistant into trials of diuretic adjuvant therapy can bias the trials toward the null. For example in the Renal Optimization Strategies Evaluation (ROSE) trial the placebo group produced 8.3L of urine with standard therapy, a result difficult to improve upon. ${ }^{33}$ Rapidly identifying responders and non-responders to decongestive therapy will allow more selective enrollment of patients that will not respond adequately to standard therapy into trials of novel therapies.

\section{Limitations}

There are several limitations that warrant discussion. While the equations employed to predict sodium and fluid output were derived from well-established physiologic principals and validated in this cohort, the validation cohort is still a small single center study and thus should undergo additional external validation. Importantly, several parameters in this cohort 
such as high incidence of hyponatremia, significant renal impairment and younger age than found in registry studies reinforces that these were highly selected patients at a tertiary care center and that validation is required. Furthermore, despite extraordinary efforts to ensure highly accurate timed urine collection in these patients, $12 \%$ had overt errors leading to study termination and likely many more had errors that were not reported or detected by the study staff. As a result, the "gold standard" employed here of a 6-hour urine collection is likely less than perfect and the results may have been different if all patients had indwelling urinary catheters. As a result, multicenter external "validation" of the sodium prediction equation will likely need to utilize outcomes such as improved length of stay or readmission rates with care guided by predicted sodium vs. usual care. Furthermore, due to the capacitance introduced into the urinary system by the bladder, incomplete bladder emptying prior to and at the last urination during the 6-hour collection will decrease precision of results of both the timed urine collection and the spot urine samples. Intravenous bumetanide was chosen for this proof of concept study due to its highly reproducible pharmacokinetics. Given the variable duration half-life of furosemide, and the unpredictable rate of absorption of many oral diuretics, further research will be necessary to determine if the current results are applicable to diuretics other than IV bumetanide. While the goal of the current study was proof of concept that sodium output could be accurately predicted, additional research will be necessary to evaluate the association with clinical outcomes and compare predicted sodium output with simpler metrics of sodium excretion such as sodium concentration and fractional excretion of sodium. Lastly, substituting the a priori time constant of 2.5 hours with 3.25 hours in Equation 1 improves the accuracy of the equation at higher sodium outputs. However, this was a data driven finding and will require validation in additional subjects before it should be applied. Nevertheless, despite the limitations described above, given the known substantial limitations of monitoring diuresis with fluid and weight loss, we feel that judicious but immediate application of these findings to research and clinical care remains warranted.

\section{Conclusion}

Early prediction of the cumulative natriuretic response to a dose of intravenous bumetanide is possible with high accuracy using inexpensive laboratory tests performed in a spot urine sample and an equation derived from well-established renal physiologic principles. This new tool provides the opportunity for rapid diagnosis of poor diuretic natriuretic response and may facilitate improved therapy and enrollment into clinical trials. Future research will be necessary to validate these findings and explore the ideal application of this tool.

\section{Supplementary Material}

Refer to Web version on PubMed Central for supplementary material.

\section{Acknowledgements}

We would like to thank Alan J. Testani for developing the online calculators.

Sources of Funding

Circ Heart Fail. Author manuscript; available in PMC 2017 January 01. 
NIH Grants, K23HL114868, L30HL115790 (JT), K23DK097201 (FPW) and K24DK090203 (CP): The funding source had no role in study design, data collection, analysis or interpretation. This publication was made possible by Clinical and Translational Science Award Grant Number UL1 TR000142 from the National Center for Advancing Translational Science (NCATS), a component of the National Institutes of Health (NIH). Its contents are solely the responsibility of the authors and do not necessarily represent the official view of NIH.

\section{References}

1. Giamouzis G, Kalogeropoulos A, Georgiopoulou V, Laskar S, Smith AL, Dunbar S, Triposkiadis F, Butler J. Hospitalization epidemic in patients with heart failure: risk factors, risk prediction, knowledge gaps, and future directions. J Card Fail. 2011; 17:54-75. [PubMed: 21187265]

2. Fonarow GC, Corday E. Overview of acutely decompensated congestive heart failure (ADHF): a report from the ADHERE registry. Heart failure reviews. 2004; 9:179-185. [PubMed: 15809815]

3. Bradley SM, Levy WC, Veenstra DL. Cost-consequences of ultrafiltration for acute heart failure: a decision model analysis. Circulation Cardiovascular quality and outcomes. 2009; 2:566-573. [PubMed: 20031894]

4. Gheorghiade M, Filippatos G, De Luca L, Burnett J. Congestion in acute heart failure syndromes: an essential target of evaluation and treatment. The American Journal of Medicine. 2006; 119:S3-S10. [PubMed: 17113398]

5. Gheorghiade M, Follath F, Ponikowski P, Barsuk JH, Blair JE, Cleland JG, Dickstein K, Drazner MH, Fonarow GC, Jaarsma T, Jondeau G, Sendon JL, Mebazaa A, Metra M, Nieminen M, Pang PS, Seferovic P, Stevenson LW, van Veldhuisen DJ, Zannad F, Anker SD, Rhodes A, McMurray JJ, Filippatos G. Assessing and grading congestion in acute heart failure: a scientific statement from the acute heart failure committee of the heart failure association of the European Society of Cardiology and endorsed by the European Society of Intensive Care Medicine. European journal of heart failure. 2010; 12:423-433. [PubMed: 20354029]

6. Gheorghiade M, Pang PS. Acute heart failure syndromes. J Am Coll Cardiol. 2009; 53:557-573. [PubMed: 19215829]

7. Gheorghiade M, Vaduganathan M, Fonarow GC, Bonow RO. Rehospitalization for Heart Failure: Problems and Perspectives. J Am Coll Cardiol. 2013; 61:391-403. [PubMed: 23219302]

8. Yancy CW, Jessup M, Bozkurt B, Butler J, Casey DE Jr, Drazner MH, Fonarow GC, Geraci SA, Horwich T, Januzzi JL, Johnson MR, Kasper EK, Levy WC, Masoudi FA, McBride PE, McMurray JJ, Mitchell JE, Peterson PN, Riegel B, Sam F, Stevenson LW, Tang WH, Tsai EJ, Wilkoff BL. 2013 ACCF/AHA guideline for the management of heart failure: a report of the American College of Cardiology Foundation/American Heart Association Task Force on Practice Guidelines. J Am Coll Cardiol. 2013; 62:e147-e239. [PubMed: 23747642]

9. Lindenfeld J, Albert NM, Boehmer JP, Collins SP, Ezekowitz JA, Givertz MM, Katz SD, Klapholz M, Moser DK, Rogers JG, Starling RC, Stevenson WG, Tang WH, Teerlink JR, Walsh MN. HFSA 2010 Comprehensive Heart Failure Practice Guideline. J Card Fail. 2010; 16:e1-e194. [PubMed: 20610207]

10. McMurray JJ, Adamopoulos S, Anker SD, Auricchio A, Bohm M, Dickstein K, Falk V, Filippatos G, Fonseca C, Gomez-Sanchez MA, Jaarsma T, Kober L, Lip GY, Maggioni AP, Parkhomenko A, Pieske BM, Popescu BA, Ronnevik PK, Rutten FH, Schwitter J, Seferovic P, Stepinska J, Trindade PT, Voors AA, Zannad F, Zeiher A, Bax JJ, Baumgartner H, Ceconi C, Dean V, Deaton C, Fagard R, Funck-Brentano C, Hasdai D, Hoes A, Kirchhof P, Knuuti J, Kolh P, McDonagh T, Moulin C, Reiner Z, Sechtem U, Sirnes PA, Tendera M, Torbicki A, Vahanian A, Windecker S, Bonet LA, Avraamides P, Ben Lamin HA, Brignole M, Coca A, Cowburn P, Dargie H, Elliott P, Flachskampf FA, Guida GF, Hardman S, Iung B, Merkely B, Mueller C, Nanas JN, Nielsen OW, Orn S, Parissis JT, Ponikowski P. ESC guidelines for the diagnosis and treatment of acute and chronic heart failure 2012: The Task Force for the Diagnosis and Treatment of Acute and Chronic Heart Failure 2012 of the European Society of Cardiology. Developed in collaboration with the Heart Failure Association (HFA) of the ESC. European journal of heart failure. 2012; 14:803-869. [PubMed: 22828712]

11. Mentz RJ, Kjeldsen K, Rossi GP, Voors AA, Cleland JG, Anker SD, Gheorghiade M, Fiuzat M, Rossignol P, Zannad F, Pitt B, O'Connor C, Felker GM. Decongestion in acute heart failure. European journal of heart failure. 2014; 16:471-482. [PubMed: 24599738] 
12. Kociol RD, McNulty SE, Hernandez AF, Lee KL, Redfield MM, Tracy RP, Braunwald E, O'Connor CM, Felker GM. Markers of decongestion, dyspnea relief, and clinical outcomes among patients hospitalized with acute heart failure. Circulation Heart failure. 2013; 6:240-245. [PubMed: 23250981]

13. Testani JM, Brisco MA, Kociol RD, Jacoby D, Bellumkonda L, Parikh CR, Coca SG, Tang WH. Substantial discrepancy between fluid and weight loss during acute decompensated heart failure treatment: Important lessons for research and clinical care. Am J Med. 2015; 128:776-83.e4. [PubMed: 25595470]

14. Guyton, AC.; Hall, JE. Textbook of medical physiology. Philadelphia: Saunders; 2000.

15. Brenner, BM.; Rector, FC. Brenner \& Rector's the kidney. Philadelphia: Saunders Elsevier; 2008.

16. Ali SS, Olinger CC, Sobotka PA, Dahle TG, Bunte MC, Blake D, Boyle AJ. Loop diuretics can cause clinical natriuretic failure: a prescription for volume expansion. Congestive heart failure (Greenwich, Conn). 2009; 15:1-4.

17. Verbrugge FH, Nijst P, Dupont M, Penders J, Tang WH, Mullens W. Urinary composition during decongestive treatment in heart failure with reduced ejection fraction. Circulation Heart failure. 2014; 7:766-772. [PubMed: 25037309]

18. Testani JM, Brisco MA, Turner JM, Spatz ES, Bellumkonda L, Parikh CR, Tang WH. Loop diuretic efficiency: a metric of diuretic responsiveness with prognostic importance in acute decompensated heart failure. Circulation Heart failure. 2014; 7:261-270. [PubMed: 24379278]

19. Mehta RH, Rogers JG, Hasselblad V, Tasissa G, Binanay C, Califf RM, O'Connor CM. Evaluation Study of Congestive Heart F and Pulmonary Artery Catheterization Effectiveness Trial I. Association of weight change with subsequent outcomes in patients hospitalized with acute decompensated heart failure. The American Journal of Cardiology. 2009; 103:76-81. [PubMed: 19101234]

20. Stevens LA, Levey AS. Measurement of kidney function. Med Clin North Am. 2005; 89:457-473. [PubMed: 15755462]

21. Levey AS, Stevens LA, Schmid CH, Zhang YL, Castro AF 3rd, Feldman HI, Kusek JW, Eggers P, Van Lente F, Greene T, Coresh J. A new equation to estimate glomerular filtration rate. Ann Intern Med. 2009; 150:604-612. [PubMed: 19414839]

22. Kelly RA, Wilcox CS, Mitch WE, Meyer TW, Souney PF, Rayment CM, Friedman PA, Swartz SL. Response of the kidney to furosemide. II. Effect of captopril on sodium balance. Kidney Int. 1983; 24:233-239. [PubMed: 6355617]

23. Wilcox CS, Mitch WE, Kelly RA, Skorecki K, Meyer TW, Friedman PA, Souney PF. Response of the kidney to furosemide. I. Effects of salt intake and renal compensation. J Lab Clin Med. 1983; 102:450-458. [PubMed: 6886524]

24. Brater DC, Day B, Burdette A, Anderson S. Bumetanide and furosemide in heart failure. Kidney Int. 1984; 26:183-189. [PubMed: 6503136]

25. Rudy DW, Voelker JR, Greene PK, Esparza FA, Brater DC. Loop diuretics for chronic renal insufficiency: a continuous infusion is more efficacious than bolus therapy. Ann Intern Med. 1991; 115:360-366. [PubMed: 1863026]

26. Ward A, Heel RC. Bumetanide. A review of its pharmacodynamic and pharmacokinetic properties and therapeutic use. Drugs. 1984; 28:426-464. [PubMed: 6391889]

27. Du Bois D, Du Bois EF. A formula to estimate the approximate surface area if height and weight be known. 1916. Nutrition. 1989; 5:303-311. discussion 312-3. [PubMed: 2520314]

28. Robinson JD, Lupkiewicz SM, Palenik L, Lopez LM, Ariet M. Determination of ideal body weight for drug dosage calculations. Am J Hosp Pharm. 1983; 40:1016-1019. [PubMed: 6869387]

29. Harris PA, Taylor R, Thielke R, Payne J, Gonzalez N, Conde JG. Research electronic data capture (REDCap)--a metadata-driven methodology and workflow process for providing translational research informatics support. Journal of biomedical informatics. 2009; 42:377-381. [PubMed: 18929686]

30. Valente MA, Voors AA, Damman K, Van Veldhuisen DJ, Massie BM, O'Connor CM, Metra M, Ponikowski P, Teerlink JR, Cotter G, Davison B, Cleland JG, Givertz MM, Bloomfield DM, Fiuzat M, Dittrich HC, Hillege HL. Diuretic response in acute heart failure: clinical characteristics and prognostic significance. Eur Heart J. 2014; 35:1284-1293. [PubMed: 24585267] 
31. Shrestha K, Singh D, Testani JM, Verbrugge FH, Dupont M, Mullens W, Tang WH. Insufficient natriuretic response to continuous intravenous furosemide is associated with poor long-term outcomes in acute decompensated heart failure. J Card Fail. 2014; 20:S40-S41.

32. Waldreus N, Hahn RG, Jaarsma T. Thirst in heart failure: a systematic literature review. European journal of heart failure. 2013; 15:141-149. [PubMed: 23180606]

33. Chen HH, Anstrom KJ, Givertz MM, Stevenson LW, Semigran MJ, Goldsmith SR, Bart BA, Bull DA, Stehlik J, LeWinter MM, Konstam MA, Huggins GS, Rouleau JL, O'Meara E, Tang WH, Starling RC, Butler J, Deswal A, Felker GM, O'Connor CM, Bonita RE, Margulies KB, Cappola TP, Ofili EO, Mann DL, Davila-Roman VG, McNulty SE, Borlaug BA, Velazquez EJ, Lee KL, Shah MR, Hernandez AF, Braunwald E, Redfield MM. Low-dose dopamine or low-dose nesiritide in acute heart failure with renal dysfunction: the ROSE acute heart failure randomized trial.

JAMA. 2013; 310:2533-2543. [PubMed: 24247300] 


\section{Clinical Perspective}

The primary goal in most hospitalizations for acute decompensated heart failure (ADHF) is the treatment of volume overload. As a result, accurately monitoring the progress and success of diuretic therapy is of critical importance. Currently fluid and weight loss are the most commonly utilized monitoring parameters, but these metrics are notoriously inaccurate/not collected and require significant delay between administration of the diuretic and availability of the data. Given the well-described pharmacokinetics of the loop diuretics, we hypothesized that the cumulative sodium output should be predictable from a spot urine sample obtained shortly after diuretic administration. We prospectively enrolled 50 ADHF patients undergoing diuresis with IV loop diuretics and performed supervised 6 hour timed urine collections following IV bumetanide administration. Using a sodium prediction equation and urine sodium and creatinine obtained from a spot urine 1 or 2 hours after diuretic administration, we found an excellent ability to predict a poor diuretic response (AUC $=0.95,95 \%$ CI 0.89-1.0, $\mathrm{p}<0.0001$ ). The sodium prediction equation significantly outperformed net fluid output and change in weight obtained by hospital staff for clinical care of the patient. Although additional validation is required, these findings suggest that monitoring of diuretic response can be performed with improve accuracy and much more rapidly using a spot urine sample and a sodium prediction equation. 

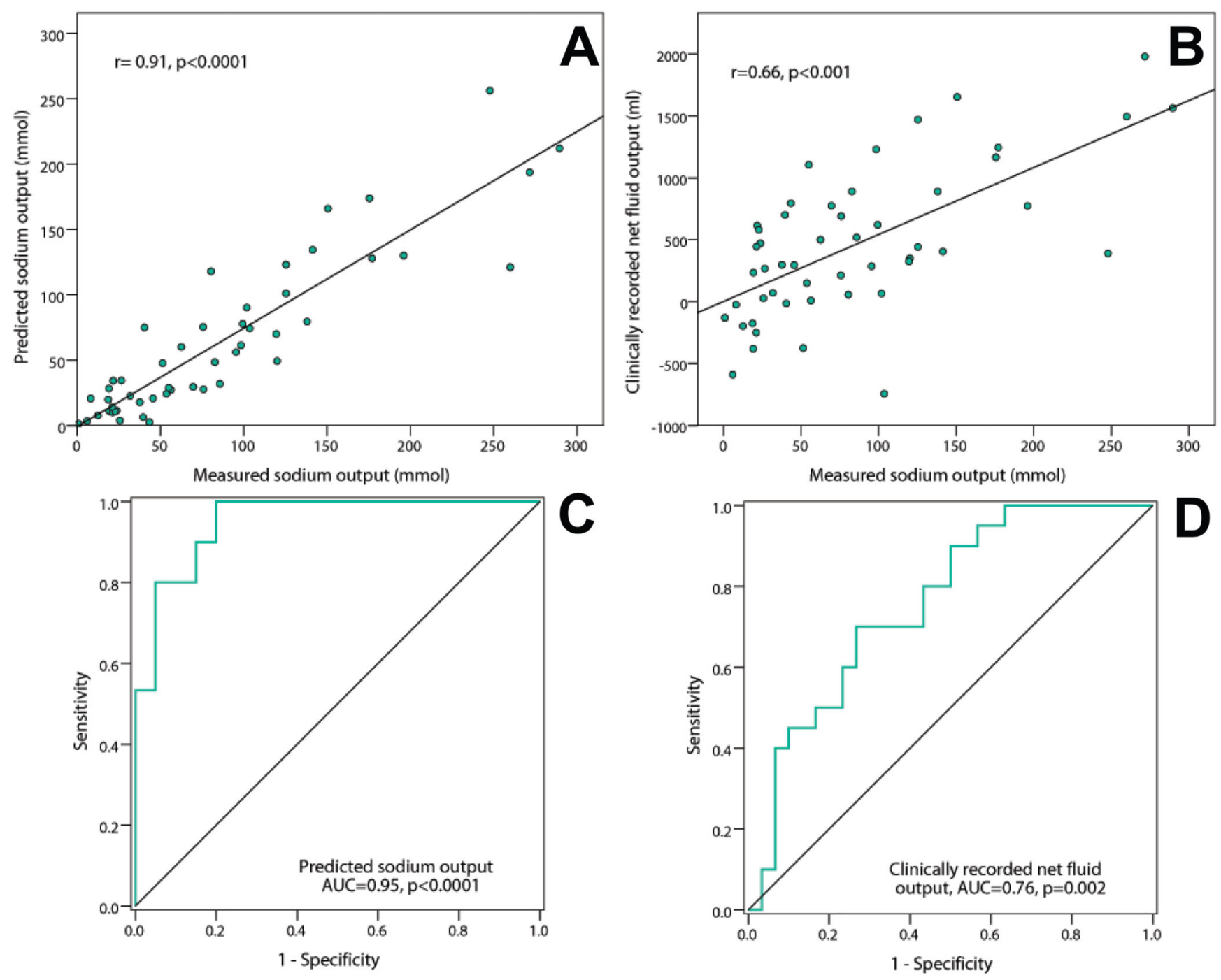

Figure 1.

Correlation plots (panel A \& B) and receiver operating characteristics curves (Panel B \& C) comparing the relationship between the sodium output prediction equation (A \& C) and clinically recorded net fluid output (B \&D) with 6-hour cumulative measured sodium output Sodium prediction calculations in panel $\mathrm{A}$ and $\mathrm{C}$ were made with Equation 1 using the two hour time point. Clinically recorded net fluid output represents the 7AM to 3PM nursing shift where fluid balance is calculated by the clinical staff and the parameter that same day diuretic dosing decisions are frequently made upon. 


\section{Table 1}

\section{Characteristics of the study population}

\begin{tabular}{lc}
\hline Characteristics & $\mathbf{N = 5 0}$ \\
\hline Demographics & \\
Age & $58.94 \pm 13.9$ \\
White race & $72.0 \%$ \\
Male & $64.0 \%$ \\
Past Medical History & \\
Hypertension & $59.6 \%$ \\
Diabetes & $42.9 \%$ \\
Gout & $16.3 \%$ \\
Ischemic heart failure etiology & $26.5 \%$ \\
Medications (Baseline) & \\
Angiotensin converting enzyme inhibitor or receptor blocker & $93.9 \%$ \\
Beta blocker & $76.0 \%$ \\
Thiazide type diuretic & $24.0 \%$ \\
Spironolactone & $48.0 \%$ \\
Digoxin & $20.4 \%$ \\
Loop diuretic dose day prior to study (mg furosemide equivalents) & $100(80-160)$ \\
Laboratory Value & \\
Serum sodium (mmol/L) & $135.2 \pm 3.7$ \\
Blood urea nitrogen (mg/dL) & $37(23.8-64.2)$ \\
Creatinine (mg/dL) & $55(30-76)$ \\
Glomerular filtration rate (mL/min/1.73m $\left.{ }^{2}\right)$ & $60.0 \%$ \\
Glomerular filtration rate $<60 \mathrm{~mL} / \mathrm{min} / 1.73 \mathrm{~m}^{2}$ & $24.0 \%$ \\
Glomerular filtration rate $<30 \mathrm{~mL} / \mathrm{min} / 1.73 \mathrm{~m}^{2}$ & \\
Functional Status / Ejection Fraction & $29.2 \pm 17.7$ \\
Left ventricular ejection fraction $(\%)$ & \\
Ejection fraction $>40 \%$ & \\
\hline
\end{tabular}


Table 2

Correlations with measured sodium output

\begin{tabular}{lcccc}
\hline Parameter & \multicolumn{3}{c}{ Correlation with measured } \\
& \multicolumn{2}{c}{ cumulative sodium output } \\
& $\mathbf{r}$ & $\mathbf{r}^{\mathbf{2}}$ & $\mathbf{p}$ \\
\hline Predicted sodium output (Two-hour sample) & 0.91 & 0.83 & $<0.001$ \\
Predicted sodium output (One-hour sample) & 0.85 & 0.72 & $<0.001$ \\
Clinically recorded net fluid balance from corresponding nursing shift ${ }^{*}$ & 0.66 & 0.44 & $<0.001$ \\
24-hour clinically recorded net fluid balance & 0.72 & 0.52 & $<0.001$ \\
24-hour clinically recorded weight loss & 0.41 & 0.17 & 0.006 \\
Bumetanide dose & 0.11 & 0.01 & 0.441 \\
Urine sodium (1 hour) & 0.70 & 0.49 & $<0.001$ \\
Urine sodium (2 hours) & 0.71 & 0.50 & $<0.001$ \\
Fractional excretion of sodium (1 hour) & 0.66 & 0.44 & $<0.001$ \\
Fractional excretion of sodium (2 hours) & 0.65 & 0.42 & $<0.001$ \\
\hline
\end{tabular}

* Represents the 7AM to 3PM nursing shift that fluid balance is calculated by the clinical staff as part of usual care and the parameter that same day diuretic dosing decisions are generally made on. 


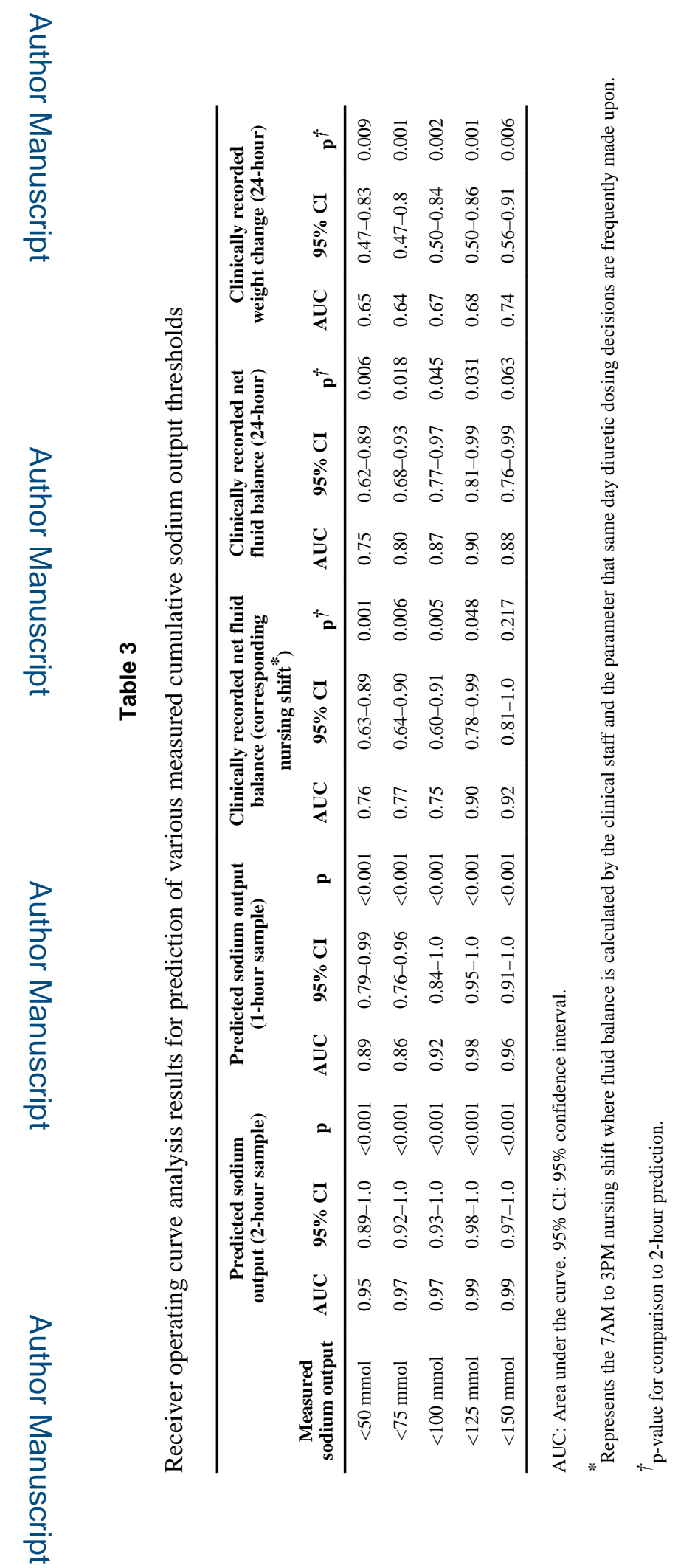

Circ Heart Fail. Author manuscript; available in PMC 2017 January 01. 


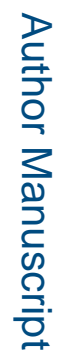

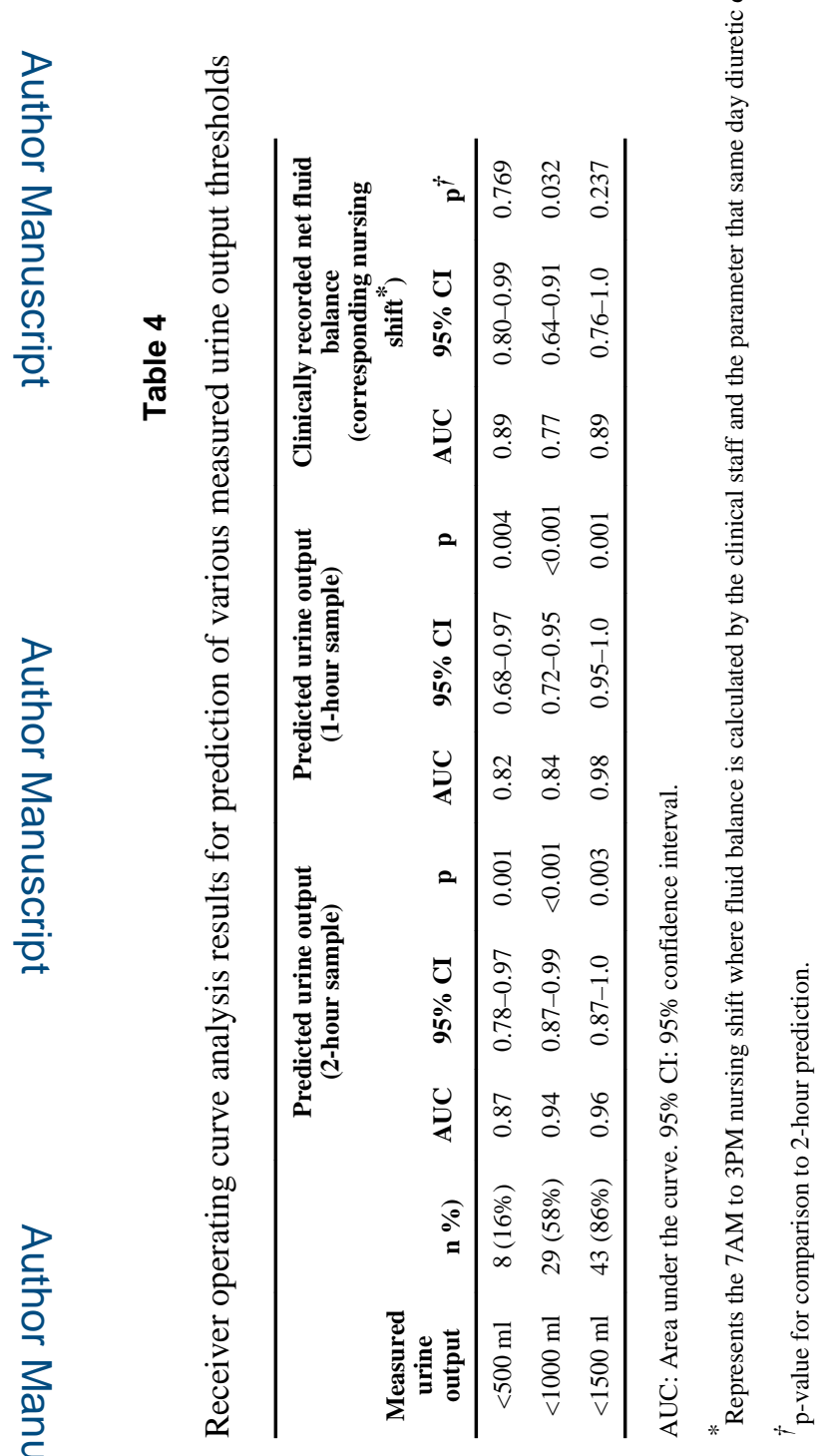

